\title{
Consent and confidentiality in children
}

SADJ September 2020, Vol. 75 No. 8 p462 - p464

\author{
LM Sykes', E Crafford ${ }^{2}$
}

\section{INTRODUCTION}

Confidentiality is central to the establishment and preservation of trust between a doctor and their patient, yet is one of the lesser-discussed principles of medical bioethics. A "duty of confidence arises when one person discloses information to another in circumstances where it is reasonable to expect that information to be held in confidence". 1

Its moral basis is in that it should improve patient welfare, and as such, it is encompassed during all aspects of the treatment process, beginning with the initial consultation where patient autonomy and informed consent are first addressed.

\section{Obtaining consent}

Ethically, there are three key elements required for valid consent:

1. Threshold elements entail the patient being sufficiently competent to understand and make a voluntary decision.

2. Information elements relate to the dentist's duty to disclose all relevant information, as well as to recommend an appropriate plan of action.

3. Consent elements refer to the patient's ability to decide for or against the treatment and to authorise it. ${ }^{2}$ Meeting these criteria involves a two way communication process wherein the clinician must first establish the patient's desires, and then provide them with adequate relevant and trustworthy information, in a clear and understandable manner in order for them to make an educated decision.

The General Dental Council (GDC) guidelines state "The clinician must obtain valid consent before starting any treatment or investigation regardless of whether they are the first member of a team to see the patient or involved after other team members have already seen them.

\section{Author affiliations:}

1. Leanne M Sykes: BSc, BDS, MDent, IRENSA, Dip Forensic Path, Dip ESMEA, Head of Department of Prosthodontics, University of Pretoria, Pretoria, South Africa. ORCID Number: 0000-0002-2002-6238

2. Elmine Crafford: $B C h D, B C h D$ Hons, Oral Medicine, MChD OMP, Senior Specialist Department of Oral Medicine and Periodontics, University of Pretoria, Pretoria, South Africa.

Corresponding author: Leanne M Sykes

Head of Department of Prosthodontics,

University of Pretoria, Pretoria, South Africa.

Email: leanne.sykes@up.ac.za

Author contributions:

1. Leanne M Sykes: Primary author - $60 \%$

2. Elmine Crafford: Second author - $40 \%$

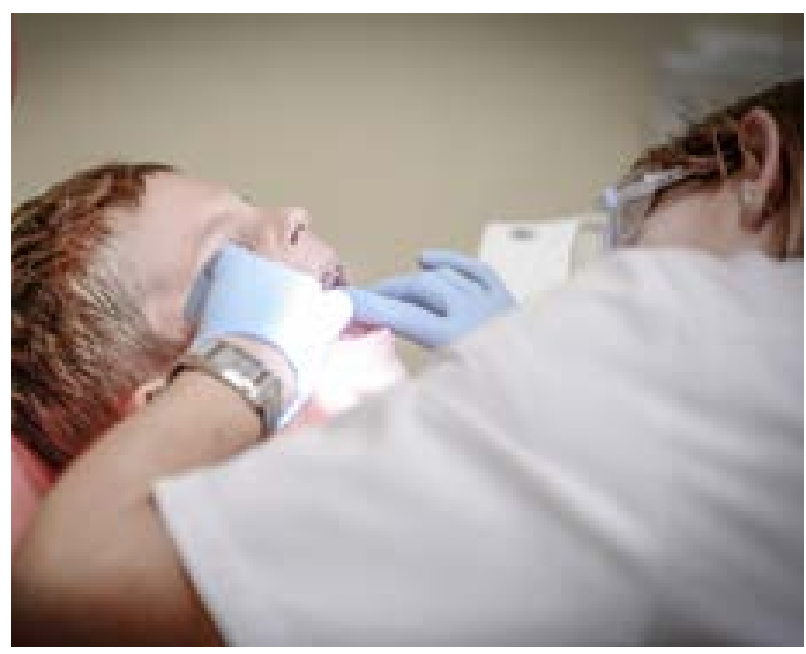

They should find out what the patient wants to know and provide clear answers to these queries, as well as added information on other pertinent issues they think patients should be aware of. This includes treatment options, risks and potential benefits, costs and time involved, the likely prognosis and guarantees, and the consequences of no treatment. They should also recommend the option they deem to be most suitable and in the patient's best interest, and then allow the patient sufficient time for consideration before making their final decision. ${ }^{3}$

Throughout this process the patient must be guaranteed of full honesty and confidentiality. Practitioners need to be aware that during this interaction they will gain access to personal information that places them in a position of power over their patients. This privilege must never be forgotten or abused by them disclosing any information or confidences without the knowledge and explicit consent of the patient. ${ }^{4}$

While it goes without saying that a patient's privacy and dignity needs to be respected at all times, confidentiality is not absolute. Besides it being an ethical issue, it is also a legal obligation ${ }^{5}$, and as such there are legitimate exceptions where disclosure may be allowed.

These include:

- When the patient has consented.

- When instructed by a court of law.

- When it is in the publics' interest. ${ }^{1}$

- If they pose a danger to themselves or to others.

- In a deceased patient, with the written consent of his or her next-of-kin or the executor of their estate, and in the case of a minor under the age of 14 years, with the written consent of the parent or guardian. ${ }^{4}$

This last proviso raises a question regarding the rights of children. 


\section{Confidentiality and consent in children}

The Childrens' Act of the Medical Dental Protection Society states that "Every child has the right to confidentiality regarding his or her health status, except when maintaining such confidence is not in their own best interest" (MDP act 28). ${ }^{5}$ Thus, in a situation where a child wishes to withhold sensitive information from their parents, this right to confidentiality should be allowed if the child is deemed to be mature enough and it is in their best interest to not disclose. ${ }^{1}$

Ethically however, the doctor still has a duty to try and persuade the child to inform their parents or to allow them to do so. However, if they suspect that the child may actually be at risk form their parents, then they have a responsibility to inform the relevant authorities.

\section{Note: there is a distinction between "In the public interest, and what the public is interested in". ${ }^{1}$}

\section{Public curiosity is not a justifiable reason to breach confidentiality.}

In SA there are laws regarding the age of responsibility, which were drafted to protect minors. The "Bill of Rights" defines a 'child' as 'a person under the age of 18 years'. This allows all people under the age of 18 years to the protection guaranteed by section 28 of the Bill of Rights and the provisions of the Children's Act. ${ }^{6}$

It is also the age below which parental consent is needed for most activities. However, there seems to be duplicity in the legislature on some issues particularly relevant to SA where children below the age of 18 are allowed to make their own decisions.

\section{Examples include:}

The age at which a child can consent to an HIV test or his/her own vaccination (12 years), age at which a child can agree to donate his/her body or any specific tissue in the event of his/her death (16 years), age at which a person can consent to donate his/her organs (e.g. kidneys) while alive (18 years), and age at which a male child can consent to being circumcised or a female child can consent to a virginity test (16 years).

In terms of criminality, the age at which a child can be tried and convicted for a criminal act varies depending on the situation and the offence in order to protect them from strict punitive sentences. " "Children under the age of criminal responsibility are not treated as criminals", ${ }^{8}$ although in South Africa Doli Incapax is set at the low age of 12 years. $^{9}$

How then is it that a child cannot consent to their own dental treatment, and where does this leave a dentist who has been requested to carry out a specific procedure, but the child explicitly asks that their parents are not informed? Not only do they have to get parental consent legally, but more than likely the parents will also be the ones responsible for paying the accounts. This may result in situations where ethical and legal arguments collide. The following hypothetical case scenario is used to illustrate a debate around an ethico-legal dilemma.

\section{Case scenario}

A teenage girl presents for dental treatment and requests that you place 4 anterior veneers on her maxillary incisors. While acknowledging that you are not a trained psychologist, it becomes very clear from the discussion that she has a low self-esteem, which seems to have stemmed from her self-consciousness about her smile.

Despite being clearly distressed and anxious, she presents with a mature understanding about the procedure, including the risks, benefits, and aesthetic limitations. She also explicitly asks you to not inform her parents about your discussion or the proposed treatment. As an ethical practitioner you are obliged to respect both her autonomy and request for confidentiality. However, she is still legally a minor thus in addition to her assent, you still need to obtain parental consent. How will you handle this situation in each of the following, slightly differing, circumstances?

1. In your opinion, the treatment is not necessary from a cosmetic perspective and does not justify preparation and sacrificing of sound enamel on 4 virgin teeth. It would be prudent to refuse treatment, thus also making it easier to avoid any ethical dilemmas about informing the parents and breaching confidentiality.

Best practice would be to acknowledge her aesthetic concerns, but educate her about the procedure, and the unnecessary risks to sound tooth structure. Advise her to wait until she is 18 years old, when she may re-consider her request from a more mature perspective.

2. You agree that the veneers could improve her smile significantly, and are confident that you can carry out the procedure with minimal tooth preparations being needed. However you will need parental consent to commence as well as to ensure they able and willing to pay for the clinical and laboratory costs?

If you inform them, you will be breaking the patient's trust and going against her strict requests. You fully believe this intervention will be of physical and psychological benefit to her, and are confident that the parents will agree to the proposed treatment. It would be easy to justify this breach in confidentiality by arguing that the potential beneficence out weighs the "indiscretion".

In addition, her autonomy will still have been respected. It would be tempting to argue that despite her initial upset, she will "probably be very happy later". Can you make these assumptions? Does this make it ethically justifiable to disregard her privacy? Should you rather refuse treatment until such time as you are able to gain parental consent?

3. You have the same deliberations as in scenario 2 above and decide to go ahead and speak to her parents. Sadly this time they refuse to give permission despite your persistence that the veneers will have both psychological and aesthetic benefits, and will be minimally invasive. In this situation, she will have endure a broken promise, a breach in confidentiality, and a loss of trust on top of the disappointment of not 
being allowed her desired treatment. The patient may react with anger, frustration or rebellion towards the dentist and/or her parents, could become more depressed and self-conscious, or may exhibit any number of other psychologically destructive behaviors. Can you afford to take these risks?

\section{DISCUSSION}

This case scenario was merely an example to illustrate the many factors that can come into play when dealing with issues of consent and confidentiality, particularly in minors. However there could be many other instances where an adolescent may request confidentiality such as for bleaching, minor orthodontic tooth movement, extraction of an unaesthetic retained deciduous tooth or a mal-aligned permanent tooth or for closure of diastema.

All of these procedures carry a low risk and are minimally damaging physically, but could have major psychological benefits for the youth. At the same time, they may have already approached their parents about the issue and met with a negative response, or could have been too embarrassment to discuss their concerns out of a fear of being considered vain and self-obsessed.

They may even feel guilty about asking for cosmetic procedures especially if they know it not essential and will have financial implications for their parents. The dentist then finds themselves in the middle of a complex dynamic where they are willing and able to help the child, but at the same time have an obligation and legal duty to obtain parental consent.

A slightly different but related challenge is seen, but not restricted to situations where the parents are divorced, and one agrees to the treatment while the other refuses. The question then arises as to who has the final say? Is it the father, the mother, the parent who has custody or the one who will be paying for the treatment?

According to the South African law, "Minors under the age of fourteen or eighteen years need the consent of their parents or guardians to medical treatment or operations respectively.

In the event of a conflict between the child's father and mother, the father's views settle the matter unless they go against the child's medical interests. Where the parents or guardians have delegated their power to consent to medical interventions upon their children to persons acting in loco parentis, such as relatives or teachers, the latter's consent suffices. The supreme court is also vested, as the ultimate guardian of minors, with the power to authorize the intervention in question". ${ }^{10}$

Thus in the situation of elective dental treatment for a minor, if the two parents cannot reach a compromise, the child may become the innocent pawn and be denied help based on the law rather than what would be in their best interest psycho-socially. We as dentists are not trained psychologists, however as health care practitioners we have a duty to consider the child's best interests, and should perhaps refer the family for joint counselling.

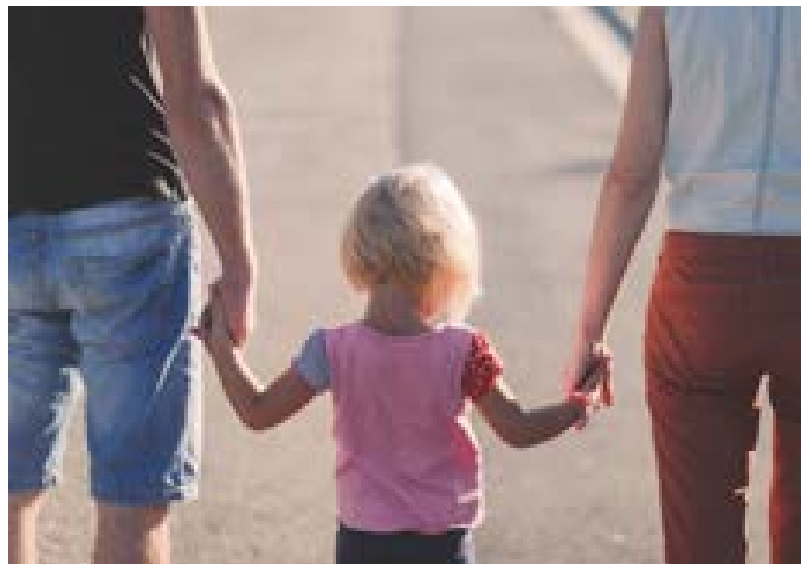

\section{CONCLUSION}

As is often the case in ethical and legal debates, there are many grey areas. While the law may dictate that a practitioner follows a specific course of action, they may not feel ethically comfortable complying with this. The dilemma revolves around which master to obey. Does acting in the patient's best interest trump adherence to the law?

This paper cannot answer these questions, but seeks to alert practitioner to be cognizant of the complexities within medico-legal ethics. As professionals we should be encouraged to constantly challenge our own thoughts and beliefs, and be modest enough to engage in collegial deliberations with colleagues or other knowledgeable experts whenever we ourselves are unsure.

\section{References}

1. Blightman, K, Griffiths SE, Danbury C. Patient confidentiality: when can a breach be justified? Accessed at: https://academic.oup.com/bjaed/article-abstract/14/2/52/271401. Accessed on: 28-04-2020.

2. Beauchamps, $T$ and Childress, JF. Principles of Biomedical ethics. $5^{\text {th }}$ edition. Oxford University Press. 2000.

3. General Dental Council. Guidelines for doctors: confidentiality. Accessed at: https://www.gdc-uk.org/; Accessed on 26-04-2020.

4. Health Professions Council of South Africa Guidelines for Good Practice in the Health care Professions as promulgated in the Government Gazette R717. 2006; (2 ${ }^{\text {nd }}$ ed.) B. Booklet 2; Section 13. Professional Confidentiality.

5. Medical Protection Society. Respect for patient confidentiality. Accessed at: www.medicalprotection.org >advice-booklets $>$ respect. Accessed on: 28-04-2020.

6. Bill of Rights of the Constitutional Court of South Africa. Accessed at: https://www.concourt.org.za/index.php/constitution/your-rights/the-bill-of-rights. Accessed on: 06-05-2020.

7. Mahery P, Proudlock, P. Legal guide to age thresholds for children and young people. Children's Institute, University of Cape Town: University of Western Cape, 2011.

8. Skelton A, Badenhorst, C. The Criminal Capacity of Children in South Africa. International Developments \& Considerations for a Review. The Child Justice Alliance, c/o The Children's Rights Project, Community Law Centre: University of Western Cape. 2011.

9. Cipriani D. Children's Rights and the Minimum Age of Criminal Responsibility. Publishing A, editor. Accessed at https:// books.google.co.za/books?isbn=1409496635. on 07-07-2015. Ashgate Publishing, Ltd. 2013; 252.

10. Carstens PA. Informed Consent in Medical law. The South African Medico Legal perspectives. Accessed at: new.samls. co.za/node/354. Accessed on 19-02-2020. 